\title{
ANALISIS KERAGAAN AGROINDUSTRI TAHU KULIT DI KELURAHAN GUNUNG SULAH KECAMATAN WAY HALIM KOTA BANDAR LAMPUNG
}

\author{
(The Performance Analysis of "Tahu Kulit" Agroindustry in Gunung Sulah Village at Way Halim \\ Sub District Bandar Lampung City)
}

Fadila Shafira, Dyah Aring Hepiana Lestari, Muhammad Irfan Affandi

Jurusan Agribisnis, Fakultas Pertanian, Universitas Lampung, Jl. Prof. Dr. Soemantri Brojonegoro No. 1 Bandar Lampung 35145, Telp. 081382159268,e-mail: fadilashafira12@gmail.com

\begin{abstract}
This research aims to analyze the raw material procurement system based on the elements of raw materials, the performance of production, income and added value associated with the processing activities, marketing mix and distribution channel in product marketing activities, and the role of support services. The research method used was a case study method on three "tahu kulit" agro-industries in Gunung Sulah Urban Village, Way Halim Sub-district, Bandar Lampung City. The location of research was determined purposively with the consideration that the Gunung Sulah Urban Village was the center of "tahu kulit" production in Bandar Lampung. Research was conducted in February - March 2017 and data analysis method used in this research was qualitative and quantitative descriptive analysis. The results showed that the procurement of raw materials in the three agro-industries was in accordance with the elements of procurement of raw materials. The production performance of the three agro-industries had not been good because it had not fulfilled the productivity and flexibility components. Revenues of the three agro-industries were good because the values of $R / C$ ratio were more than 1 and processing of these three agro-industries adds positive value. Three agro-industries had implemented a marketing mix and there are two channels in marketing activities of "tahu kulit" product. Support services utilized by agro-industries gave positive impact to agro-industry activities.
\end{abstract}

Key words: added value, agroindustry, income, performance, tahu kulit

\section{PENDAHULUAN}

Agroindustri merupakan industri berbasis sumber daya, hal ini dinilai strategis mengingat Indonesia merupakan satu dari sedikit negara di daerah tropis yang memiliki keragaman hayati (biodiversity) cukup besar. Indonesia memiliki iklim, suhu dan kelembaban yang cocok untuk pertumbuhan tanaman pangan pokok, maka hampir seluruh tanaman pangan pokok tersebut (biji-bijian, umbiumbian dan kacang-kacangan asli Indonesia) dapat tumbuh dengan baik. Salah satu jenis tanaman pangan yang sangat dibutuhkan oleh sebagian besar penduduk Indonesia adalah kedelai (Glysine $\max (\mathrm{L})$ Merril) (Tambunan 2003).

Kedelai merupakan komoditas tanaman pangan terpenting setelah padi dan jagung. Kedelai memiliki arti penting dalam industri pangan dan pakan. Tidak hanya sebagai bahan baku industri dan pakan, tetapi kedelai mampu memperbaiki gizi masyarakat bila dimasukkan dalam pola konsumsi sehari-hari, karena mengandung kadar protein yang tinggi, vitamin dan mineral serta sumber lemak, baik dalam bentuk segar maupun olahan seperti tempe, tahu, kecap, tauco, dan sebagainya.

Berdasarkan data BPS Kota Bandar Lampung pada 2016, sebagian besar perkembangan ekonomi Kota Bandar Lampung didukung oleh sektor industri pengolahan. Pembangunan perekonomian daerah di Kota Bandar Lampung berdasarkan Produk Domestik Regional Bruto Kota Bandar Lampung atas dasar harga berlaku menurut lapangan usaha tahun 2016, industri pengolahan memberikan kontribusi sebesar Rp 6.287.775,50 atau sebesar 20,03 persen dan sebanyak 15,24 persen adalah industri pengolahan makanan dan minuman (BPS Kota Bandar Lampung 2016).

Salah satu industri pengolahan makanan atau agroindustri yang telah berkembang di Kota Bandar Lampung adalah agroindustri tahu. Berdasarkan data yang diperoleh dari Primer Koperasi Produsen Tempe Tahu Indonesia Kota Bandar Lampung atau Primkopti tahun 2016, yaitu terdapat 238 pengrajin tahu di Kota Bandar Lampung. Salah satunya terdapat pada Kelurahan Gunung Sulah sebanyak 115 pengrajin tahu. 
Kelurahan Gunung Sulah merupakan sentra agroindustri tahu di Kota Bandar Lampung (Primkopti 2016).

Agroindustri merupakan subsistem yang melengkapi rangkaian sistem agribisnis dengan fokus kegiatan berbasis pengolahan dan peningkatan nilai tambah komoditas hasil pertanian. Kegiatan yang terdapat pada agroindustri tahu kulit mencakup kegiatan pengadaan bahan baku, kegiatan pengolahan, dan kegiatan pemasaran. Seluruh kegiatan dalam agroindustri tahu, dapat didukung oleh jasa layanan pendukung. Kegiatan pengadaan bahan baku merupakan kegiatan yang sangat penting pada agroindustri, termasuk agroindustri tahu. Dalam proses transformasi suatu bahan baku menjadi produk, sangat ditentukan dengan kinerja agroindustri, apabila kinerja agroindustri baik maka agroindustri akan memperolah nilai tambah dan pendapatan yang tinggi.

Kegiatan memasarkan tahu dapat didukung dengan penerapan bauran pemasaran (marketing mix), yaitu 4P (produk, harga, tempat, dan promosi) pada agroindustri agar produk yang dihasilkan lebih bernilai jual tinggi. Seluruh kegiatan utama pada agroindustri tahu tersebut tentu akan berjalan lebih efektif apabila didukung dengan adanya peran jasa layanan pendukung. Oleh sebab itu, penelitian ini bertujuan untuk menganalisis pengadaan bahan baku berdasarkan elemen-elemen pengadaan bahan baku, menganalisis kinerja produksi, pendapatan dan nilai tambah produk, mengetahui bauran pemasaran, dan menganalisis peranan jasa layanan pendukung bagi agroindustri.

\section{METODE PENELITIAN}

Metode penelitian yang digunakan adalah studi kasus. Metode studi kasus merupakan salah satu metode penelitian yang dilakukan secara intensif, terperinci dan mendalam terhadap suatu organisme atau gejala tertentu selama kurun waktu tertentu (Arikunto 2004). Penelitian dilakukan pada tiga agroindustri tahu yang berada di Kelurahan Gunung Sulah, Kecamatan Way Halim Kota Bandar Lampung. Penentuan lokasi dilakukan secara sengaja (purposive) dengan pertimbangan bahwa Kelurahan Gunung Sulah merupakan sentra produksi tahu di Kota Bandar Lampung.

Populasi dalam penelitian adalah seluruh agroindustri tahu di Kelurahan Gunung Sulah, yaitu 115 pengrajin. Populasi telah dikelompokan berdasarkan rata-rata per produksi atau per hari dan lama berusaha. Untuk skala produksi besar jumlah produksi $>90 \mathrm{~kg}$ per hari, skala produksi sedang dengan jumlah produksi $\leq 90 \mathrm{~kg}$ per hari, dan untuk skala produksi kecil $\leq 55 \mathrm{~kg}$ per hari. Responden ditentukan secara sengaja (purposive) yaitu untuk membandingkan tiga agroindustri berdasarkan skala usaha, responden skala produksi besar Agroindustri Tahu SJ, skala produksi sedang Agroindustri Tahu SY, dan skala produksi kecil Agroindustri Tahu SD. Responden pedagang untuk saluran pemasaran diambil secara snowball sampling dengan pertimbangan karena tidak ada informasi yang pasti mengenai jumlah pedagang tahu.

Data yang digunakan data primer dan sekunder. Data primer diperoleh dari wawancara, pengamatan serta pencatatan langsung. Data sekunder diperoleh dari studi literatur, laporanlaporan, publikasi, dan pustaka lainnya yang berhubungan dengan penelitian ini, serta lembaga atau instansi yang terkait dalam penelitian ini, seperti BPS, Primkopti, Dinas Koperasi, Industri dan Perdagangan, dan lain-lain. Pengambilan data dilaksanakan pada Februari - Maret 2017.

Metode analisis data yang digunakan pada penelitian ini adalah metode analisis deskriptif kualitatif dan analisis deskriptif kuantitatif. Analisis yang digunakan untuk tujuan pertama yaitu analisis pengadaan bahan baku berupa penerapan berdasarkan elemen-elemen bahan baku yang meliputi kuantitas, kualitas, waktu, biaya, dan organisasi. Analisis yang digunakan untuk tujuan kedua yaitu analisis kinerja, pendapatan dan nilai tambah produk pada agroindustri tahu kulit. Analisis kinerja diukur berdasarkan komponen produktivitas, kapasitas, kualitas, kecepatan pengiriman, dan fleksibilitas menurut Prasetya dan Lukiastuti (2009). Berikut merupakan uraian rumus produktivitas dan kapasitas sebagai berikut:

1) Produktivitas

Produktivitas dari agroindustri dihitung dari unit yang diproduksi (output) atau produk tahu dengan masukan yang digunakan atau tenaga kerja dengan menggunakan rumus berikut :

Produktivitas $=\frac{\text { Output }}{\text { Input }}$.

2) Kapasitas

Kapasitas yaitu suatu ukuran yang menyangkut kemampuan dari agroindustri dalam menghasilkan output dari suatu proses produksi. Kapasitas diperoleh dari actual output yaitu output berupa tahu yang diproduksi 
dan design capacity yaitu kapasitas maksimal memproduksi tahu kulit. Kapasitas agroindustri dihitung dengan menggunakan rumus :

$$
\text { Capacity Utilization }=\frac{\text { Actual Output }}{\text { Design Capacity }} \ldots \ldots \text {... }
$$

\section{Keterangan:}

Actual output : Output yang diproduksi (kg) Design capacity : Kapasitas memproduksi (kg)

Analisis pendapatan digunakan untuk melihat seberapa besar keuntungan yang diperoleh agroindustri tahu kulit dan apakah usaha yang dilakukan tersebut layak untuk diusahakan berdasarkan nilai $\mathrm{R} / \mathrm{C}$ rasio. Analisis pendapatan secara matematis dapat dirumuskan sebagai berikut:

$$
\begin{aligned}
& \Pi=\text { TR }- \text { TC } \ldots \ldots \ldots \ldots \ldots \ldots \\
& \Pi=\text { Y.PY }-\sum X i . P X i-\text { BTT } \\
& \text { R/C }=\text { TR } / \text { TC } \ldots \ldots \ldots \ldots \ldots \ldots \ldots \ldots \ldots \ldots
\end{aligned}
$$

Keterangan:

$\Pi \quad=$ Pendapatan $(\mathrm{Rp})$

$\mathrm{TR}=$ Total revenue atau penerimaan total $(\mathrm{Rp})$

$\mathrm{TC}=$ Total cost atau total biaya (Rp)

$\mathrm{R} / \mathrm{C}=$ Nisbah penerimaan dan biaya

$\mathrm{Y}=$ Produksi tahu $(\mathrm{Kg})$

Py = Harga tahu (Rp)

$\mathrm{Xi} \quad=$ Faktor produksi $(\mathrm{i}=1,2,3, \ldots . ., \mathrm{n})$

Pxi = Harga faktor produksi ke-i $(\mathrm{Rp})$

BTT $=$ Biaya tetap total $(\mathrm{Rp})$

Menurut Soekartawi (2010) kriteria pengambilan keputusan adalah:

a) Jika $\mathrm{R} / \mathrm{C}>1$, maka usaha tersebut mengalami keuntungan.

b) Jika $\mathrm{R} / \mathrm{C}<1$, maka usaha mengalami kerugian.

c) Jika $\mathrm{R} / \mathrm{C}=1$, maka usaha ini mengalami impas.

Analisis nilai tambah digunakan untuk melihat besarnya nilai tambah kedelai yang diolah menjadi tahu kulit. Perhitungan nilai tambah yang dilakukan menggunakan metode Hayami (1987) dalam Putri, Hasyim, dan Lestari (2016). Kriteria nilai tambah (NT) adalah sebagai berikut:

a) Jika NT >0, pengembangan untuk agroindustri tahu sudah memberi nilai tambah yang positif.

b) Jika NT $<0$, berarti pengembangan agroindustri tahu memberi nilai tambah yang negatif.

Metode analisis data yang digunakan tujuan ketiga untuk menganalisis bagaimana penerapan bauran pemasaran berupa 4 P (Place, Price, Place, dan Promotion) menurut Kotler dan Keller (2008). Metode analisis data untuk tujuan keempat adalah digunakan untuk menganalisis pemanfaatan jasa layanan pendukung serta bagaimana peran dan fungsi jasa layanan pendukung tersebut dalam kegiatan produksi yang dilakukan oleh agroindustri tahu kulit.

\section{HASIL DAN PEMBAHASAN}

\section{Pengadaan Bahan Baku}

Pengadaan bahan baku dilakukan untuk menunjang pelaksanaan proses produksi yang ada di dalam suatu agroindustri. Bahan baku yang digunakan ketiga agroindustri tahu kulit untuk adalah kedelai. Selain itu ketiga agroindustri tahu kulit juga memerlukan bahan baku penunjang dalam memproduksi tahu kulit. Bahan baku penunjang seperti garam, kayu bakar, plastik kemasan, dan lainnya.

Perbedaan skala produksi antara Agroindustri Tahu SJ, Agroindustri Tahu SY, dan Agroindustri Tahu SD yang menyebabkan perbedaan kuantitas dalam pengadaan bahan baku kedelai dan bahan baku penunjang. Kegiatan pengadaan bahan baku pada ketiga agroindustri tahu dapat dilihat pada Tabel 1. Berdasarkan Tabel 1 dapat diketahui bahwa seluruh komponen pengadaan bahan baku pada Agroindustri Tahu SJ, Agroindustri Tahu SY, dan Agroindustri Tahu SD sudah sesuai elemen pengadaan bahan baku, dikarenakan kegiatan pengadaan bahan baku yang diharapkan sudah sesuai dengan kenyataan pada ketiga agroindustri.

\section{Analisis Kinerja}

Analisis kinerja produksi dilakukan dilihat dari aspek produktivitas, kapasitas, kualitas, kecepatan pengiriman, dan fleksibilitas seperti penelitian Sari, Zakaria, dan Affandi (2015).

1) Produktivitas dan Kapasitas

Hasil perhitungan produktivitas dan kapasitas dapat dilihat pada Tabel 2. Standar nilai produktivitas tenaga kerja yang digunakan adalah berdasarkan penelitian Tian (2013) bahwa produktivitas agroindustri tahu kulit sebesar $18,75 \mathrm{~kg} / \mathrm{HOK}$, apabila produktivitas lebih besar dari standar nilai 18,75 maka produktivitas sudah baik dan sebaliknya apabila kurang dari 18,75 maka belum baik. 


\section{JIIA, VOLUME 6 No. 3, AGUSTUS 2018}

Tabel 1. Pengadaan bahan baku tiga agroindustri tahu berdasarkan elemen-elemen pengadaan bahan baku

\begin{tabular}{|c|c|c|c|c|}
\hline \multirow{2}{*}{$\begin{array}{c}\text { Elemen- } \\
\text { elemen } \\
\text { pengadaan } \\
\text { bahan baku }\end{array}$} & \multirow[b]{2}{*}{ Harapan } & \multicolumn{3}{|c|}{ Kenyataan } \\
\hline & & Agroindustri Tahu SJ & Agroindustri Tahu SY & Agroindustri Tahu SD \\
\hline Kuantitas & $\begin{array}{l}\text { Kedelai tersedia } \\
\text { dalam jumlah yang } \\
\text { banyak dan tidak } \\
\text { terbatas. }\end{array}$ & $\begin{array}{l}\text { Kedelai jumlahnya banyak } \\
\text { dan sudah terpenuhi dengan } \\
\text { baik yaitu } 125 \mathrm{~kg} \text { untuk } \\
\text { satu kali produksi. }\end{array}$ & $\begin{array}{l}\text { Kedelai jumlahnya } \\
\text { banyak dan sudah } \\
\text { terpenuhi dengan baik } \\
\text { yaitu rata-rata } 80 \mathrm{~kg} \\
\text { untuk satu kali produksi. }\end{array}$ & $\begin{array}{l}\text { Kedelai jumlahnya } \\
\text { banyak dan sudah } \\
\text { terpenuhi dengan baik } \\
\text { yaitu rata-rata } 40 \mathrm{~kg} \\
\text { untuk satu kali produksi. }\end{array}$ \\
\hline Kualitas & $\begin{array}{l}\text { Kualitas kedelai } \\
\text { impor dengan ukuran } \\
\text { besar seragam, } \\
\text { kedelai sudah bersih, } \\
\text { kulit berwarna kuning } \\
\text { dan biji berwarna } \\
\text { putih bersih } \\
\text { kekuningan dan tidak } \\
\text { mudah rapuh. }\end{array}$ & $\begin{array}{l}\text { Kedelai yang digunakan } \\
\text { merupakan kedelai impor } \\
\text { yang sudah bersih, ukuran } \\
\text { besar seragam, kulit } \\
\text { berwarna kuning dan biji } \\
\text { berwarna putih bersih } \\
\text { kekuningan dan tidak } \\
\text { mudah rapuh. }\end{array}$ & $\begin{array}{l}\text { Kedelai yang digunakan } \\
\text { merupakan kedelai impor } \\
\text { dengan ukuran besar } \\
\text { seragam, sudah bersih, } \\
\text { kulit berwarna kuning } \\
\text { dan biji berwarna putih } \\
\text { bersih kekuningan dan } \\
\text { tidak mudah rapuh. }\end{array}$ & $\begin{array}{l}\text { Kedelai yang digunakan } \\
\text { merupakan kedelai impor } \\
\text { dengan ukuran besar } \\
\text { seragam dan sudah } \\
\text { bersih, biji berwarna } \\
\text { putih bersih kekuningan } \\
\text { dan tidak mudah rapuh. }\end{array}$ \\
\hline Waktu & $\begin{array}{l}\text { Pengadaan kedelai } \\
\text { dilakukan satu } \\
\text { sampai dua kali } \\
\text { dalam satu minggu. }\end{array}$ & $\begin{array}{l}\text { Pengadaan kedelai } \\
\text { dilakukan dalam tiga hari } \\
\text { sekali atau dua kali dalam } \\
\text { satu minggu. }\end{array}$ & $\begin{array}{l}\text { Pengadaan kedelai } \\
\text { dilakukan dalam tiga hari } \\
\text { sekali atau dua kali } \\
\text { dalam satu minggu. }\end{array}$ & $\begin{array}{l}\text { Pengadaan kedelai } \\
\text { dilakukan dalam } \\
\text { lima hari sekali atau satu } \\
\text { kali dalam satu minggu. }\end{array}$ \\
\hline Biaya & $\begin{array}{l}\text { Biaya yang } \\
\text { dikeluarkan untuk } \\
\text { kedelai berkisar } \\
\text { sebesar Rp } 6.700 \text { - } \\
7.000 / \mathrm{kg} .\end{array}$ & $\begin{array}{l}\text { Biaya untuk kedelai adalah } \\
\text { Rp } 7.000 / \text { kg. }\end{array}$ & $\begin{array}{l}\text { Biaya untuk kedelai } \\
\text { adalah Rp } 7.000 / \mathrm{kg} .\end{array}$ & $\begin{array}{l}\text { Biaya untuk kedelai } \\
\text { adalah Rp } 7.000 / \mathrm{kg} .\end{array}$ \\
\hline Organisasi & $\begin{array}{l}\text { Terdapat lembaga } \\
\text { atau organisasi yang } \\
\text { selalu menyediakan } \\
\text { kedelai berkelanjutan. }\end{array}$ & $\begin{array}{l}\text { Agroindustri memperoleh } \\
\text { kedelai dari CV. Puranti } \\
\text { Makmur sebagai penyedia } \\
\text { kedelai impor. }\end{array}$ & $\begin{array}{l}\text { Agroindustri memperoleh } \\
\text { kedelai dari CV. Multi } \\
\text { Makmur sebagai } \\
\text { penyedia kedelai impor. }\end{array}$ & $\begin{array}{l}\text { Agroindustri memperoleh } \\
\text { kedelai dari CV. Multi } \\
\text { Makmur sebagai } \\
\text { penyedia kedelai impor. }\end{array}$ \\
\hline
\end{tabular}

Tabel 2. Produktivitas dan kapasitas tiga agroindustri tahu kulit

\begin{tabular}{lrc}
\hline \multicolumn{1}{c}{ Responden } & $\begin{array}{c}\text { Produktivitas } \\
(\mathrm{Kg} / \mathrm{HOK})\end{array}$ & Kapasitas \\
\hline Agroindustri Tahu SJ & 34,53 & 1,00 \\
Agroindustri Tahu SY & 23,61 & 0,88 \\
Agroindustri Tahu SD & 16,70 & 0,96 \\
\hline
\end{tabular}

Berdasarkan penelitian Wiyono dan Baksh (2015) kapasitas usaha tahu pada industri rumah tangga sebesar 0,56 atau 56 persen telah berproduksi secara baik. Kapasitas produksi tahu tersebut, dapat dijadikan standar pengukuran kapasitas agroindustri tahu karena persamaan komoditas produk tahu. Apabila $\geq$ dari standar nilai maka kapasitas baik.

2) Kualitas

Berdasarkan SNI 01-3142-1998 tentang syarat mutu tahu yang dapat digunakan sebagai pengukuran kualitas atau mutu tahu yang dapat dijadikan acuan dalam memproduksi tahu. Ketiga agroindustri tahu kulit merupakan industri rumah tangga sehingga belum menggunakan SNI sebagai acuan kualitas tahu.
Ketiga agroindustri juga belum melakukan pengujian terkait syarat mutu tahu karena pemilik beranggapan bahwa tidak perlu untuk melakukan pengujian terhadap produk yang di produksi, dan pemilik juga beranggapan apabila dalam kegiatan produksi sudah menggunakan bahan baku yang berkualitas baik maka menghasilkan tahu berkualitas baik.

3) Kecepatan pengiriman

Waktu pengiriman produk yang dipesan untuk sampai ke pelanggan tidak memerlukan waktu yang banyak untuk mengirimkan produknya. Pada ketiga agroindustri tahu, melakukan pengiriman produk setiap hari dalam seminggu.

4) Fleksibel

Fleksibilitas diukur melalui tiga dimensi, yaitu yang pertama adalah kecepatan proses transformasi kedelai menjadi tahu kulit, proses pembuatan tahu kulit hanya memerlukan waktu $10-12$ jam untuk satu kali produksi. Kedua yaitu kemampuan bereaksi untuk berubah dalam volume untuk menghasilkan $1 \mathrm{~kg}$ tahu, pada Agroindustri Tahu SJ membutuhkan 1,03 kg kedelai untuk $1 \mathrm{~kg}$ tahu kulit, Agroindustri 
Tahu SY membutuhkan 1,06 kg kedelai untuk 1 kg, dan Agroindustri Tahu SD membutuhkakan $1,08 \mathrm{~kg}$ kedelai untuk $1 \mathrm{~kg}$. Ketiga adalah kemampuan dari proses produksi untuk memproduksi produk secara serempak, hal ini belum dapat dilakukan ketiga agroindustri tahu kulit untuk mengolah produk dengan bahan baku yang sama.

\section{Analisis Pendapatan}

Pendapatan yang diperoleh ketiga agroindustri tahu kulit menunjukkan bagaimana keadaan ketiga agroindustri tahu kulit tersebut, apakah sudah menguntungkan atau tidak secara ekonomi dengan melihat nisbah atau perbandingan antara penerimaan dengan biaya (R/C Ratio). Perhitungan pendapatan dan $\mathrm{R} / \mathrm{C}$ rasio pada ketiga agroindustri tahu dapat dilihat pada Tabel 5 . Besarnya pendapatan yang diperoleh ketiga agroindustri tahu berbeda-beda sesuai dengan jumlah produksi agroindustri tahu kulit

Analisis pendapatan dapat diketahui bahwa jumlah pendapatan yang diterima Agroindustri Tahu SJ lebih besar jika dibandingkan dengan Agroindustri Tahu SY dan Agroindustri Tahu SD. Dilihat dari nisbah penerimaan ( $\mathrm{R} / \mathrm{C}$ rasio) terhadap biaya tunai maupun biaya total rata-rata produksi per hari, diketahui bahwa Agroindustri Tahu SJ, Agroindustri Tahu SY dan Agroindustri Tahu SD sudah menguntungkan karena nisbah penerimaan ( $\mathrm{R} / \mathrm{C}$ rasio) baik terhadap biaya tunai dan biaya total rata-rata produksi per hari sudah lebih dari satu. Nisbah penerimaan ( $\mathrm{R} / \mathrm{C}$ rasio) Agroindustri Tahu SJ yang berskala produksi besar lebih tinggi dibandingkan Agroindustri Tahu SY dan Agroindustri Tahu SD. Hal ini disebabkan karena Agroindustri Tahu SJ memproduksi lebih banyak tahu dibandingkan Agroindustri Tahu SY dan Agroindustri Tahu SD. Nilai R/C rasio tidak hanya dipengaruhi jumlah produksi, tetapi juga dipengaruhi besarnya biaya sarana produksi yang digunakan selama kegiatan produksi. Hasil penelitian ini sejalan dengan hasil penelitian Sarfan (2016) tentang analisis keuntungan dan kelayakan usaha pembuatan tahu yang menunjukkan bahwa Industri Tahu $\mathrm{M}$ sudah menguntungkan dan layak diusahakan karena $\mathrm{R} / \mathrm{C}$ rasio sebesar 1,56

\section{Nilai Tambah Agroindustri Tahu}

Analisis nilai tambah yang dilakukan pada Agroindustri Tahu SJ, Agroindustri Tahu SY dan Agroindustri Tahu SD adalah analisis rata-rata dalam kurun waktu satu bulan. Berdasarkan Tabel
3, diperoleh nilai tambah rata-rata ketiga agroindustri. Perhitungan rata-rata input bahan baku dari ketiga agroindustri tahu kulit yaitu sebanyak $2.483,33 \mathrm{~kg}$ kedelai. Nilai tambah ratarata ketiga agroindustri tahu kulit adalah sebesar Rp 7.168,42, jika dibandingkan dengan nilai tambah masing-masing agroindustri, Agroindustri Tahu SJ lebih banyak dan diatas perhitungan ratarata dibandingkan dengan Agroindustri Tahu SY dan Agroindustri Tahu SD. Nilai tambah masingmasing untuk Agroindustri Tahu SJ dan Agroindustri Tahu SY diperoleh nilai tambah sudah diatas nilai tambah rata-rata ketiga agroindustri. Sedangkan untuk Agroindustri Tahu SD memperoleh nilai tambah terkecil dan masih sedikit dibawah nilai tambah rata-rata. Berdasarkan kriteria penilaian nilai tambah, yaitu apabila NT $>0$, berarti pengembangan agroindustri tahu memberikan nilai tambah positif.

\section{Bauran Pemasaran}

Bauran pemasaran merupakan kumpulan alat pemasaran taktis terkendali produk, harga, tempat, dan promosi yang diperlukan perusahaan untuk menghasilkan respons yang diinginkannya di pasar sasaran. Ketiga agroindustri tahu yang terdapat di Kelurahan Gunung Sulah yaitu Agroindustri Tahu SJ, Agroindustri Tahu SY, dan Agroindustri Tahu SD dapat menerapkan bauran pemasaran untuk dijadikan strategi dalam kegiatan pemasaran produknya. Menurut Kotler dan Keller (2008), komponen-komponen dari bauran pemasaran terdiri dari $4 \mathrm{P}$ yaitu product (produk), price (harga), place (lokasi atau distribusi), dan promotion (promosi). Ketiga agroindustri dapat menerapkan bauran pemasaran untuk dijadikan strategi dalam kegiatan pemasaran produknya. Komponen-komponen bauran pemasaran yang sudah diterapkan Agroindustri Tahu SJ, Agroindustri Tahu SY, dan Agroindustri Tahu SD dapat dilihat pada Tabel 4.

\section{Jasa Layanan Pendukung}

Berdasarkan Tabel 6, jasa layanan pendukung yang menunjang ketiga agroindustri tahu adalah bank, pegadaian, sarana transportasi, teknologi informasi dan komunikasi, kebijakan pemerintah, dan pasar. Jasa layanan pendukung yang belum dimanfaatkan ketiga agroindustri adalah koperasi, lembaga penyuluh pertanian, dan lembaga penelitian. Bank merupakan lembaga yang bergerak di bidang keuangan yang berkaitan dengan permodalan. Dalam hal permodalan, ketiga agroindustri 
menggunakan modal pribadi tanpa bantuan bank maupun lembaga keuangan lainnya.

Tabel 3. Nilai tambah tahu kulit pada tiga agroindustri tahu di Kelurahan Gunung Sulah

\begin{tabular}{|c|c|c|c|c|c|c|}
\hline \multirow[t]{2}{*}{ No. } & \multirow{2}{*}{$\begin{array}{c}\text { Variabel } \\
\text { Output, Input, dan Harga }\end{array}$} & \multicolumn{4}{|c|}{ Nama Agroindustri Tahu } & \multirow{2}{*}{ Rata-rata } \\
\hline & & & SJ & SY & $\overline{\mathrm{SD}}$ & \\
\hline 1 & Output $(\mathrm{Kg} / \mathrm{B} \ln )$ & $\mathrm{A}$ & $3.626,00$ & $2.272,00$ & $1.200,00$ & $2.366,00$ \\
\hline 2 & Bahan Baku (Kg/Bln) & B & $3.750,00$ & $2.400,00$ & $1.300,00$ & $2.483,33$ \\
\hline 3 & Tenaga Kerja (HOK/Bln) & $\mathrm{C}$ & 105,00 & 93,75 & 71,88 & 90,21 \\
\hline 4 & Faktor Konversi & $\mathrm{d}=\mathrm{a} / \mathrm{b}$ & 0,97 & 0,95 & 0,92 & 0,95 \\
\hline 5 & Koefisien Tenaga Kerja & $\mathrm{e}=\mathrm{c} / \mathrm{b}$ & 0,03 & 0,04 & 0,06 & 0,04 \\
\hline 6 & Harga Output (Rp/Kg) & $\mathrm{f}$ & $18.600,00$ & $18.600,00$ & $18.600,00$ & $18.600,00$ \\
\hline 7 & Upah Rata-Rata Tenaga Kerja (Rp/HOK) & $\mathrm{g}$ & $40.000,00$ & $40.000,00$ & $40.000,00$ & $40.000,00$ \\
\hline \multicolumn{7}{|c|}{ Pendapatan dan Nilai Tambah $(\mathrm{Rp} / \mathrm{Kg})$} \\
\hline 8 & Harga Bahan Baku (Rp/Kg) & h & $7.000,00$ & $7.000,00$ & $7.000,00$ & $7.000,00$ \\
\hline 9 & Sumbangan Input Lain (Rp/kg) & $\mathrm{i}$ & $3.545,11$ & $3.477,10$ & $3.234,71$ & $3.418,97$ \\
\hline 10 & Nilai Output & $j=d \times f$ & $17.984,96$ & 17.608 & $17.169,23$ & $17.587,40$ \\
\hline \multirow[t]{2}{*}{11} & a. Nilai Tambah & $k=j-h-i$ & $7.439,85$ & 7130,90 & $6.934,52$ & $7.168,42$ \\
\hline & b. Rasio Nilai Tambah (\%) & $\mathrm{l}=\mathrm{k} / \mathrm{j}(\%)$ & 41,37 & 40,50 & 40,39 & 40,75 \\
\hline \multirow[t]{2}{*}{12} & a. Imbalan Tenaga Kerja & $\mathrm{m}=\mathrm{e} \times \mathrm{g}$ & 1.120 & $1.562,50$ & $2.211,54$ & $1.631,35$ \\
\hline & b. Bagian Tenaga Kerja & $\mathrm{n}=\mathrm{m} / \mathrm{k}(\%)$ & 15,05 & 21,91 & 31,89 & 22,95 \\
\hline \multirow[t]{2}{*}{13} & a. Keuntungan & $\mathrm{o}=\mathrm{k}-\mathrm{m}$ & $6.319,85$ & $5.568,40$ & $4.722,98$ & $5.537,08$ \\
\hline & b. Tingkat Keuntungan & $\mathrm{p}=\mathrm{o} / \mathrm{k}(\%)$ & 84,95 & 78,09 & 68,11 & 77,05 \\
\hline \multicolumn{7}{|c|}{ Balas Jasa untuk Faktor Produksi } \\
\hline 14 & Margin & $q=j-h$ & $10.984,96$ & 10.608 & $10.169,23$ & $10.587,40$ \\
\hline & a. Keuntungan & $\mathrm{r}=\mathrm{O} / \mathrm{q}(\%)$ & 57,53 & 52,49 & 46,44 & 52,16 \\
\hline & b. Tenaga Kerja & $\mathrm{s}=\mathrm{m} / \mathrm{q}(\%)$ & 10,20 & 14,73 & 21,75 & 15,56 \\
\hline & c. Input Lain & $\mathrm{t}=\mathrm{i} / \mathrm{q}(\%)$ & 32,27 & 32,78 & 31,81 & 32,29 \\
\hline
\end{tabular}

Tabel 4. Komponen-komponen terkait bauran pemasaran pada tiga agroindustri tahu kulit

\begin{tabular}{|c|c|c|c|c|}
\hline No & Komponen & Agroindustri Tahu SJ & Agroindustri Tahu SY & Agroindustri Tahu SD \\
\hline \multirow[t]{6}{*}{1} & Produk： & & & \\
\hline & a. Bentuk, ukuran, dan & Sesuai dengan permintaan & Sesuai dengan permintaan & Sesuai dengan permintaan \\
\hline & jumlah produksi & konsumen & konsumen & konsumen \\
\hline & b. Bentuk kemasan & Kantung plastik & Kantung plastik & Kantung plastik \\
\hline & c. Merek & Belum ada merek & Belum ada merek & Belum ada merek \\
\hline & d. Keawetan & 4 hari & 4 hari & 4 hari \\
\hline \multirow[t]{4}{*}{2} & Harga & & & \\
\hline & a. Penetapan harga & $\begin{array}{l}\text { Berdasarkan biaya produksi } \\
\text { yang dikeluarkan }\end{array}$ & $\begin{array}{l}\text { Berdasarkan biaya produksi } \\
\text { yang dikeluarkan }\end{array}$ & $\begin{array}{l}\text { Berdasarkan biaya produksi } \\
\text { yang dikeluarkan }\end{array}$ \\
\hline & b. Harga tahu kulit & Sangat terjangkau & Sangat terjangkau & Sangat terjangkau \\
\hline & c. Cara pembayaran & Secara tunai & Secara tunai & Secara tunai \\
\hline \multirow[t]{5}{*}{3} & Tempat & & & \\
\hline & a.Penjualan tahu kulit & Dipasarkan secara langsung & Dipasarkan secara langsung & Dipasarkan secara langsung \\
\hline & b. Sasaran pemasaran & Masyarakat umum & Masyarakat sekitar dan umum & Masyarakat umum \\
\hline & c. Tempat pemasaran & $\begin{array}{l}\text { Rumah produksi dan Pasar } \\
\text { Pangkung }\end{array}$ & $\begin{array}{l}\text { Rumah produksi dan Pasar } \\
\text { Tempel Way Halim }\end{array}$ & Pasar Tempel Way Dadi \\
\hline & d.Lokasi agroindustri & $\begin{array}{l}\text { Belum } \\
\text { strategis }\end{array}$ & Belum strategis & Belum strategis \\
\hline 4. & $\begin{array}{l}\text { Promosi } \\
\text { a.Cara promosi }\end{array}$ & Personal selling & Personal selling & Personal selling \\
\hline
\end{tabular}

Koperasi yang berada di lingkungan agroindustri adalah Primer Koperasi Produsen Tempe Tahu Indonesia sudah tidak aktif. Keberadaan koperasi di lingkungan agroindustri ada, tetapi pemanfaatan belum saat ini sudah tidak aktif, lalu kegiatan yang dahulu dilakukan seperti pengadaan bahan baku kedelai, kegiatan simpan pinjam, dan kegiatan lainnya juga sudah tidak dilakukan. Selain itu jasa layanan belum dimanfaatkan lembaga penyuluh pertanian dan lembaga penelitian. Lingkungan sekitar agroindustri belum terdapat lembaga penyuluh dan lembaga penelitian. Sarana transportasi yang sudah dimanfaatkan Agroindustri Tahu SJ adalah berupa mobil.

Ketiga agroindustri tahu telah memanfaatkan sarana teknologi informasi dan komunikasi. Belum terdapat kebijakan pemerintah terkait 
agroindustri tahu di Kelurahan Gunung Sulah dan sudah memanfaatkan pasar sebagai jasa layanan penunjang. Ketersediaan dan pemanfaatan jasa layanan pendukung oleh ketiga agroindustri dapat dilihat pada Tabel 6. Penelitian ini berbeda dengan hasil penelitian Aldhariana, Lestari, dan Ismono (2016) mengenai keragaan agroindustri beras siger di Provinsi Lampung. Hasil penelitian tersebut menunjukkan bahwa jasa layanan pendukung yang telah dimanfaatkan oleh agroindustri beras siger adalah lebih sedikit dibandingkan dengan agroindustri tahu di Kelurahan Gunung Sulah.

\section{KESIMPULAN}

Pengadaan bahan baku yang berdasarkan lima elemen pengadaan bahan baku yang meliputi kuantitas, kualitas, waktu, biaya, dan organisasi, sudah sesuai dengan apa yang ketiga agroindustri harapkan. Kinerja pada tiga agroindustri tahu belum baik karena belum memenuhi komponen produktivitas dan fleksibilitas. Pendapatan per produksi untuk tiga agroindustri tahu sudah baik dan menguntungkan karena $\mathrm{R} / \mathrm{C}>1$ yang artinya layak untuk diusahakan. Nilai tambah pada tiga agroindustri memberikan nilai tambah positif sehingga usaha agroindustri layak untuk dikembangkan. Kegiatan pemasaran tahu kulit ketiga agroindustri telah menerapkan bauran pemasaran (marketing mix) yang terdiri dari empat komponen, yaitu: produk, harga, tempat atau distribusi, dan promosi. Jasa layanan pendukung sudah dimanfaatkan oleh ketiga agroindustri tersebut dan berdampak positif bagi kelancaran kegiatan tiga agroindustri tahu.

\section{DAFTAR PUSTAKA}

Aldhariana SF, Lestari DAH, dan Ismono H. 2016. Keragaan agroindustri Beras Siger (kasus di Agroindustri Toga Sari Kabupaten Tulang Bawang dan Agroindustri Mekar Sari Kota Metro). JIIA, Vol 4 (3) : 217-225. http:// jurnal.fp.unila.ac.id/index.php/JIA/article/vie w/1507/1361. [1 September 2017].

Arikunto S. 2004. Prosedur Penelitian : Suatu Pendekatan Praktek. Rineka Cipta. Bandung.

BPS [Badan Pusat Statistik] Kota Bandar Lampung. 2016. Produk Domestik Regional Bruto Kota Bandar Lampung Menurut
Lapangan Usaha 2012-2016. BPS Kota Bandar Lampung. Bandar Lampung.

Hayami Y. 1987. Agricultural marketing and processing in Upland Java, A Perspektif from a Sunda Village. CGPRT Center. Bogor.

Kotler P dan Keller KL. 2008. Manajemen Pemasaran, Jilid 1. Erlangga. Jakarta.

Prasetya H dan Lukiastuti F. 2009. Manajemen Operasi. Media Pressindo. Yogyakarta.

Putri IT, Hasyim AI, Lestari DAH. 2016. Nilai tambah, bauran pemasaran (Marketing Mix) dan perilaku konsumen dalam pengambilan keputusan pembelian produk rotan (kursi teras tanggok dan kursi teras pengki) di Kota Bandar Lampung. JIIA, Vol 4 (1) : 48-55. http://jurnal.fp.unila.ac.id/index.php/JIA/articl e/view/1214/1111. [1 September 2017].

Primkopti [Primer Koperasi Produsen Tempe Tahu Indonesia] Kota Bandar Lampung. 2016. Daftar UMK Pengrajin Tahu Tempe Kota Bandar Lampung. Primkopti Kota Bandar Lampung. Bandar Lampung.

Sarfan H. 2016. Analisis keuntungan dan kelayakan usaha pembuatan tahu di Kelurahan Liabuku Kecamatan Bungi Kota Bau-Bau (studi kasus pada Industri Tahu Mekar). Skripsi. Universitas Halu Oleo. Kendari.

Sari IRM, Zakaria WA, dan Affandi MI. 2015. Kinerja produksi, nilai tambah dan strategi pengembangan agroindustri emping melinjo di Kota Bandar Lampung. JIIA, Vol 3 (4) : 18-25. http://jurnal.fp.unila.ac.id/index.php/ JIA/article/view/1013/918. [ [1 $\quad$ September 2017].

Soekartawi. 2010. Agribisnis: Teori dan Aplikasinya. Rajawali Press. Jakarta.

Tambunan TTH. 2003. Perkembangan Sektor Pertanian di Indonesia, Beberapa Isu Penting. Ghalia Indonesia. Jakarta.

Tian S. 2013. Nilai tambah pada agroindustri tahu. Jurnal Universitas Siliwangi, Vol 2 (3) : 215223. https://journal.unsil.ac.id/php?id=3093. [15 Mei 2017].

Wiyono T dan Baksh R 2015. Analisis pendapatan dan nilai tambah usaha tahu industri rumah tangga "Wajianto" di Desa Ogurandu Kecamatan Bolano Lambunu. E-Journal Agrotekbis, Vol 3 (3) : 421-426. https:// jurnal.untad.ac.id/jurnal/index.php/Agrotekbis /article/download/5106/3896. [15 Mei 2017]. 
JIIA, VOLUME 6 No. 3, AGUSTUS 2018

Tabel 5. Analisis pendapatan rata-rata produksi per hari pada tiga agroindustri tahu kulit

\begin{tabular}{|c|c|c|c|c|c|c|c|c|c|c|}
\hline \multirow{3}{*}{ No } & \multirow{3}{*}{ Uraian } & \multicolumn{9}{|c|}{ Pendapatan rata-rata per produksi } \\
\hline & & \multicolumn{6}{|c|}{ Agroindustri SJ dan SY } & \multicolumn{3}{|c|}{ Agroindustri SD } \\
\hline & & Satuan & Jumlah SJ & Jumlah SY & Harga (Rp) & Biaya (Rp) SJ & Biaya (Rp) SY & Jumlah & Harga $(\mathrm{Rp})$ & Biaya (Rp) \\
\hline \multirow[t]{4}{*}{1} & Penerimaan & & & & & & & & & \\
\hline & Tahu & $\mathrm{Kg}$ & 120,87 & 75,73 & $18.600,00$ & $2.248 .120,00$ & $1.408 .640,00$ & 40,00 & $18.600,00$ & $744.000,00$ \\
\hline & Ampas tahu basah & $\mathrm{Kg}$ & 340,00 & 249,33 & 294,12 & $100.000,00$ & $73.333,33$ & 79,33 & 294,12 & $23.333,33$ \\
\hline & Total Penerimaan & & & & & $2.348 .120,00$ & $1.481 .973,33$ & & & $767.333,33$ \\
\hline \multirow[t]{17}{*}{2} & Biaya Produksi & & & & & & & & & \\
\hline & I. Biaya Tunai & & & & & & & & & \\
\hline & Biaya Variabel & & & & & & & & & \\
\hline & Kedelai & $\mathrm{Kg}$ & 125,00 & 80,00 & $7.000,00$ & $875.000,00$ & $560.000,00$ & 43,33 & $7.000,00$ & $303.333,33$ \\
\hline & Garam & $\mathrm{Kg}$ & 0,75 & 0,5 & $8.000,00$ & $6.000,00$ & $4.000,00$ & 0,25 & $8.000,00$ & $2.000,00$ \\
\hline & Kayu bakar & kubik & 2,00 & 1,33 & $60.000,00$ & $120.000,00$ & $80.000,00$ & 0,63 & $40.000,00$ & $25.333,33$ \\
\hline & Kantong plastik & lembar & 146,67 & 86,67 & 150,00 & $22.000,00$ & $13.000,00$ & 58,33 & 150,00 & $8.750,00$ \\
\hline & Minyak goreng & $\mathrm{Kg}$ & 17,00 & 11,67 & $12.500,00$ & $212.500,00$ & $145.833,33$ & 6,00 & $12.500,00$ & $75.000,00$ \\
\hline & TKLK & $\mathrm{HOK}$ & 2,25 & 0,35 & $40.000,00$ & $90.000,00$ & $14.166,67$ & 0 & $40.000,00$ & 0 \\
\hline & Bahan bakar bensin & Liter & 7,00 & 2,00 & $6.800,00$ & $47.600,00$ & $13.600,00$ & 2,00 & $6.800,00$ & $13.600,00$ \\
\hline & Biaya listrik & $\mathrm{Rp}$ & & & & $2.333,33$ & $2.000,00$ & & & $1.333,33$ \\
\hline & Total Biaya Tunai & $\mathrm{Rp}$ & & & & $1.375 .433,33$ & $832.600,00$ & & & $429.350,00$ \\
\hline & II. Biaya Diperhitungkan & & & & & & & & & \\
\hline & Biaya Tetap & & & & & & & & & \\
\hline & TKDK & HOK & 1,25 & 2,85 & $40.000,00$ & $50.000,00$ & $114.166,67$ & 2,40 & $40.000,00$ & $95.833,33$ \\
\hline & Penyusutan & $\mathrm{Rp}$ & & & & $9.705,56$ & $6.734,72$ & & & $5.404,17$ \\
\hline & Total Biaya Diperhitungkan & $\mathrm{Rp}$ & & & & $60.127,54$ & $120.901,39$ & & & $101.237,50$ \\
\hline \multirow[t]{4}{*}{3} & Total Biaya & $\mathrm{Rp}$ & & & & $1.435 .138,89$ & $953.501,39$ & & & $530.587,50$ \\
\hline & Pendapatan & & & & & & & & & \\
\hline & Pendapatan Atas Biaya Tunai & $\mathrm{Rp}$ & & & & $972.686,67$ & $649.373,33$ & & & $337.983,33$ \\
\hline & Pendapatan Atas Biaya Total & $\mathrm{Rp}$ & & & & $912.981,11$ & $528.471,94$ & & & $236.748,83$ \\
\hline \multirow[t]{3}{*}{4} & R/C Ratio & & & & & & & & & \\
\hline & R/C Ratio Atas Biaya Tunai & $\mathrm{Rp}$ & & & & 1,71 & 1,75 & & & 1,79 \\
\hline & R/C Ratio Atas Biaya Total & $\mathrm{Rp}$ & & & & 1,64 & 1,55 & & & 1,45 \\
\hline
\end{tabular}


JIIA, VOLUME 6 No. 3, AGUSTUS 2018

Tabel 6. Ketersediaan jasa layanan pendukung disekitar lokasi tiga agroindustri tahu di Kelurahan Gunung Sulah

\begin{tabular}{|c|c|c|c|c|c|c|c|}
\hline \multirow{2}{*}{ No } & \multirow{2}{*}{$\begin{array}{l}\text { Ketersediaan } \\
\text { jasa layanan }\end{array}$} & \multicolumn{2}{|c|}{ Agroindustri Tahu SJ } & \multicolumn{2}{|c|}{ Agroindustri Tahu SY } & \multicolumn{2}{|c|}{ Agroindustri Tahu SD } \\
\hline & & Keberadaan & Pemanfaatan & Keberadaan & Pemanfaatan & Keberadaan & Pemanfaatan \\
\hline 1 & Bank & Ada & Sudah & Ada & Sudah & Ada & Sudah \\
\hline 2 & Koperasi & Ada & Belum & Ada & Belum & Ada & Belum \\
\hline 3 & Pegadaian & Ada & Sudah & Ada & Belum & Ada & Belum \\
\hline 4 & $\begin{array}{l}\text { Lembaga } \\
\text { penyuluh } \\
\text { pertanian }\end{array}$ & Tidak ada & Belum & Tidak ada & Belum & Tidak ada & Belum \\
\hline 5 & $\begin{array}{l}\text { Lembaga } \\
\text { penelitian }\end{array}$ & Tidak ada & Belum & Tidak ada & Belum & Tidak ada & Belum \\
\hline 6 & $\begin{array}{l}\text { Sarana } \\
\text { transportasi }\end{array}$ & Ada & Sudah & Ada & Sudah & Ada & Sudah \\
\hline 7 & $\begin{array}{l}\text { Teknologi } \\
\text { informasi dan } \\
\text { komunikasi }\end{array}$ & Ada & Sudah & Ada & Sudah & Ada & Sudah \\
\hline 8 & $\begin{array}{l}\text { Kebijakan } \\
\text { pemerintah }\end{array}$ & Ada & Sudah & Ada & Sudah & Ada & Sudah \\
\hline 9 & Pasar & Ada & Sudah & Ada & Sudah & Ada & Sudah \\
\hline
\end{tabular}

